16

\title{
Изменение оптических свойств оксида титана при кристаллизации
}

\author{
(C) С.В. Булярский ${ }^{1}$, Д.А. Коива ${ }^{1}$, Г.Г. Гусаров ${ }^{1}$, В.В. Светухин ${ }^{2}$ \\ ${ }^{1}$ Институт нанотехнологий микроэлектроники РАН, \\ 119991 Москва, Россия \\ ${ }^{2}$ Научно-производственный комплекс „Технологический центр“, \\ 124498 Москва, Зеленоград, Россия \\ e-mail: bulyar2954@mail.ru
}

Поступила в редакцию 11.06.2021 г.

В окончательной редакции 16.07.2021 г.

Принята к публикации 28.07.2021 г.

\begin{abstract}
Кристаллизация аморфных пленок оксида титана, синтезированных методом магнетронного распыления, проведена при температурах 700, 800 и $900^{\circ} \mathrm{C}$ в атмосфере кислорода. Показатель преломления пленок растет при кристаллизации с постоянной времени, которая зависит от температуры, что позволило определить энергию активации процесса кристаллизации порядка $0.6 \mathrm{eV}$. Модель кинетики роста нанокристаллов оксида титана, которая использована в настоящей работе, показала, что указанная энергия активации соответствует энергии диффузии вакансий кислорода. Этот процесс является определяющим для роста нанокристаллов оксида титана при отжиге в атмосфере кислорода. Изучение фотолюминесценции показало, что кристаллизация приводит к изменению отношения интенсивностей различных полос излучения. Гаснут полосы, которые связаны с вакансией кислорода. Снижение концентрации этих вакансий в пленках приводит к росту их сопротивления и стабилизации пленок во времени.
\end{abstract}

Ключевые слова: пленки оксида титана, кристаллизация, показатель преломления, фотолюминесценция.

DOI: $10.21883 /$ OS.2021.11.51645.2428-21

\section{Введение}

Тонкие пленки оксида титана находят важное применение в создании активных элементов наноэлектроники, в том числе для изготовления затворов $\operatorname{CMOS}[1,2]$, газовых сенсоров [3], солнечных элементов с гетеропереходом из $\mathrm{TiO}_{2}[4,5]$. Гетеропереход $\mathrm{TiO}_{2} /$ кремний имеет большой разрыв потенциальных кривых в валентной зоне, который создает потенциальный барьер для дырок порядка $2.0 \mathrm{eV}$ в этом случае и блокирует транспорт дырок в кремний, что повышает эффективность фотоприемников. Для этих изделий требуются стабильные тонкие пленки высокого сопротивления. Известно, что показатель преломления оксида титана увеличивается после отжига, а ширина запрещенной зоны несколько уменьшается [6,7]. Дефекты структуры определяют электронные параметры этих активных элементов во всех случаях, что заставляет подробно исследовать механизмы управления их количеством.

Пленки оксида титана часто создают методом магнетронного напыления для производства элементов наноэлектроники [8-10]. Структура таких пленок является аморфной сразу после синтеза [11]. Кристаллизация тонких пленок начинается при температурах выше $700^{\circ} \mathrm{C}$, если их отжигать в атмосфере кислорода или на воздухе $[12,13]$. Такой отжиг оксида титана изменяет фазовый состав, морфологическую структуру и содержание дефектов. Для того, чтобы пленки эффективно использовать в наноэлектронике, необходимо понимать меха- низмы кристаллизации и эволюции пленки от аморфной до нанокристаллической.

Анализ протекания процессов дефектообразования в оксиде титана проводится, как правило, путем экспериментального изучения полос излучения после обработки пленок при различных условиях [14-24]. Вакансии кислорода определяют свечение в видимой области спектра с энергией максимума полосы $2.4 \mathrm{eV}$ [16-18]. Для объяснения природы возникновения этой полосы был предложен донорно-акцепторный механизм фотолюминесценции в наноструктурах $\mathrm{TiO}_{2}$, при котором вакансии однократно ионизированного кислорода захватывают фотогенерированные электроны, тогда как поверхностные гидроксильные группы захватывают образовавшиеся дырки [20]. Полоса с максимумом излучения в области $1.2 \mathrm{eV}$ в области $1.4 \mathrm{eV}$ обусловлена ионами междоузельного титана $\mathrm{Ti}^{+4}$. Дефектные состояния, которые связаны с ионами междоузельного титана, вносят вклад в люминесценцию ближней ИК области [24]. Широкая полоса люминесценции $1.27 \mathrm{eV}$ связана с $\mathrm{Ti}_{i}^{3+}$ дефектом на поверхности нанокристалла, а полоса $1.47 \mathrm{eV}$ приписывается междоузельному $\mathrm{Ti}^{4+}$ в его объеме. Результаты рентгеновской фотоэлектронной спектроскопии подтверждают наличие как $\mathrm{Ti}_{i}^{3+}$-, так и $\mathrm{Ti}_{i}^{4+}$-дефектов в пленках и зависимость их содержания от обработки. В работе [21] сделано предположение, что полоса фотолюминесценции $(2.4 \mathrm{eV})$ в $\mathrm{TiO}_{2}$ связана с рекомбинацией свободных электронов с дырками, которые захвачены на ловушки, а красная полоса $(2.05 \mathrm{eV})$ может быть связана с комплексами междоузельного 
титана и вакансии кислорода. Было показано, что как в анатазе, так и в рутиле слабосвязанные самозахваченные экситоны фактически состоят из поляронов и дают широкие полосы излучения в видимой области спектра. Этим обусловлена полоса P5 $2.85 \mathrm{eV}$, которая создается автолокализованными экситонами $[18,21]$.

Таким образом, оптические, фотолюминесцентные свойства и содержание дефектов в тонких пленках оксида титана определяются как условиями получения, так и последующими технологическими обработками. В настоящей работе исследуются оптические и фотолюминесцентные свойства тонких пленок оксида титана, которые отжигались в атмосфере кислорода различное время и при различных температурах. Изучается поведение оптических свойств этих пленок при отжиге в атмосфере кислорода с целью получения стабильных слоев с малой электропроводностью, которая достигается снижением концентрации вакансий кислорода.

\section{Синтез и термообработка пленок}

Пленки оксида титана состава $\mathrm{TiO} x$ были синтезированы методом магнетронного распыления титановой мишени в атмосфере аргона и кислорода на термически окисленные пластины монокристаллического кремния nтипа. Подача рабочих газов в камеру осуществлялась при помощи двух автоматических регуляторов. Поток Ar составлял $20 \mathrm{~cm}^{3} / \mathrm{min}, \mathrm{O}_{2}-4.7 \mathrm{~cm}^{3} / \mathrm{min}$. Мощность магнетрона при газовом разряде равнялась $300 \mathrm{~W}$, а время напыления $3 \mathrm{~h}$.

Отжиг пленок в атмосфере кислорода осуществлялся при температурах 900, 800 и $700^{\circ} \mathrm{C}$, время отжига изменялось для того, чтобы отследить кинетику процессов кристаллизации.

\section{Морфологический и фазовый анализ $\mathrm{TiO}_{x}$ до и после отжига}

Морфологический анализ проводился с помощью растрового электронного микроскопа. Изображения образцов представлены на рис. 1 .

Поверхность исходных образцов сразу после синтеза была мелкозернистой с отдельными более крупными включениями (рис. 1,a). После отжига поверхность уплотнялась, и становилось заметным развитие крупноблочных структур с четкими границами отдельных блоков, однако просвечивающая электронная микроскопия показала, что блоки также состоят из нанокристаллов с размерами от 20 до $40 \mathrm{~nm}$.

Рентгеновский фазовый анализ показал, что пленки сразу после напыления были рентгеноаморфными. После отжига при температуре $900^{\circ} \mathrm{C}$ в течение $1 \mathrm{~h}$ пленки оксида титана начинают кристаллизоваться. При этом рентгеноаморфная фаза частично превращается в анатаз и образцы становятся двухфазными. Оже-анализ выявил, что пленки имеют состав $\mathrm{TiO}_{x}$, который равномерен по толщине всей пленки. Отношение Тi/O после отжига было близко к 0.5, поэтому пленки становились практически стехиометрическими.

Электрические измерения продемонстрировали высокое удельное сопротивление пленок после отжига.

\section{Экспериментальное исследование оптических свойств плёнок оксида титана при кристаллизации}

Компоненты мнимого показателя преломления определялись на спектральном эллипсометре SENDURO (SENTECH Instruments $\mathrm{GmbH}$ ) с пакетом математической обработки SpectraRay/3. Коэффициент поглощения вычислялся из коэффициента экстинкции по формуле:

$$
\alpha=\frac{4 \pi k}{\lambda}
$$

где $k-$ коэффициент экстинкции, $\lambda-$ длина волны.

Спектральное изменение показателя поглощения показано на рис. 2. Спектр поглощения в целом соответствует предположению о непрямых оптических переходах оксида титана [6,7], однако имеет особенность, связанную с наличием рентгеноаморфной фазы, которая проявляется в наличии края Урбаха (рис. 2,b), появление которого связано с плотностью состояний ниже дна зоны проводимости. Процессы кристаллизации при отжиге приводят к упорядочению пленок, ширина зоны их уменышается от 3.22 до $3.14 \mathrm{eV}$, что соответствует результату рентгенофазового анализа, который показал наличие нанокристаллов анатаза в пленках (рис. 2, a).

Спектры показателя преломления образцов до и после отжига показаны на рис. 3. После отжига в атмосфере кислорода при температуре $900^{\circ} \mathrm{C}$ в течение $1 \mathrm{~h}$ происходит повышение оптической плотности образцов и их показатель преломления увеличивается во всей области спектра.

Падение величины показателя преломления, когда энергии фотонов падающего света уменьшаются, указывает на нормальную дисперсию образцов (рис. 3). Результаты измерений показывают, что показатель преломления увеличивается при отжиге с 2.42 до 2.53 на длине волны гелий-неонового лазера $633 \mathrm{~nm}$, и достигает величины, близкой к показателю преломления объемного анатаза $\mathrm{TiO}_{2}$. В работе [6] отмечалось, что пленки, синтезированные золь-гельным методом, сразу после получения являются аморфными, а их показатель преломления имеет величину 1.96 при $633 \mathrm{~nm}$. В нашем случае пленки, синтезированные магнетронным распылением, имеют показатель преломления 2.42. Эти пленки являются рентгеноаморфными, однако мелкокристаллическими с размером нанокристаллов менее $5 \mathrm{~nm}$. Поэтому их показатель преломления выше. При отжиге $900^{\circ} \mathrm{C}$ увеличение показателя преломления может быть связано с термическим ростом зерен, который увеличивает плотность упаковки. Оба эти результата показывают, 


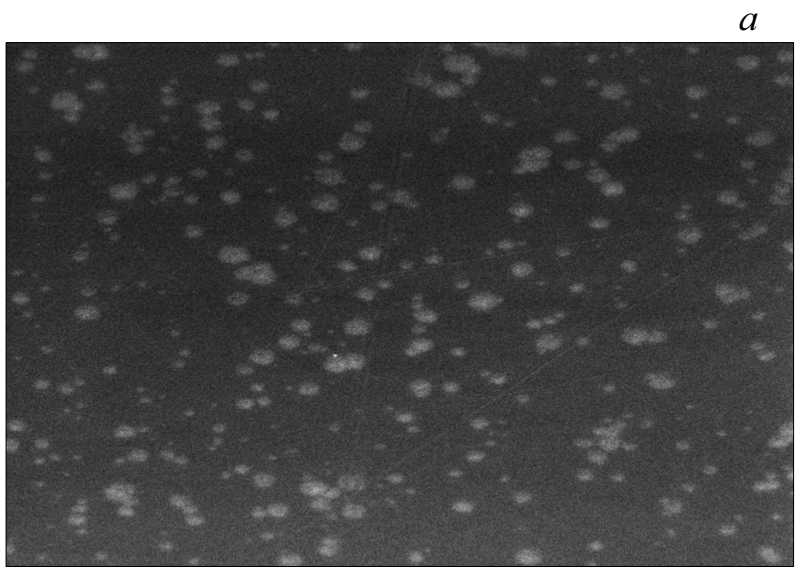

$2 \mu \mathrm{m}$

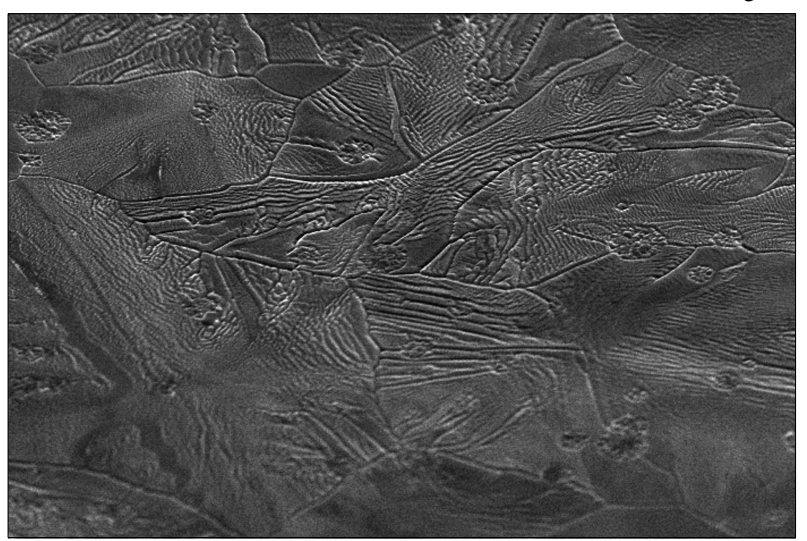

$2 \mu \mathrm{m}$

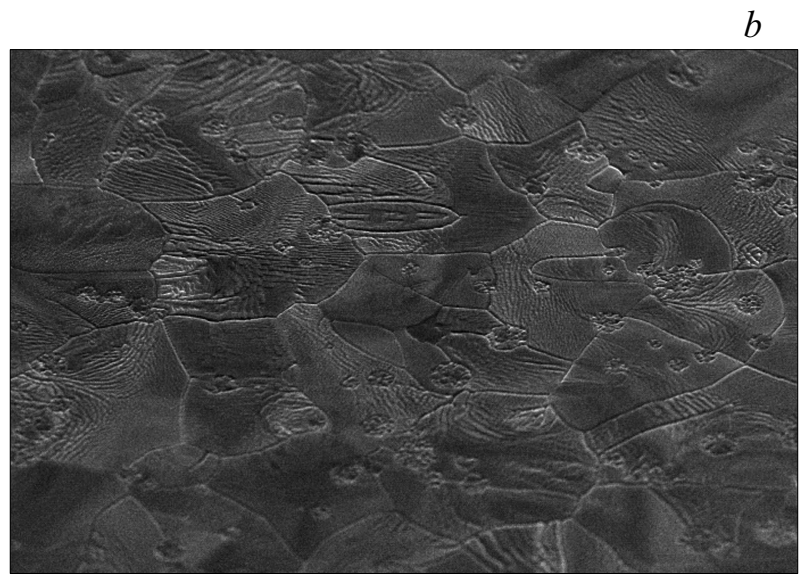

$2 \mu \mathrm{m}$

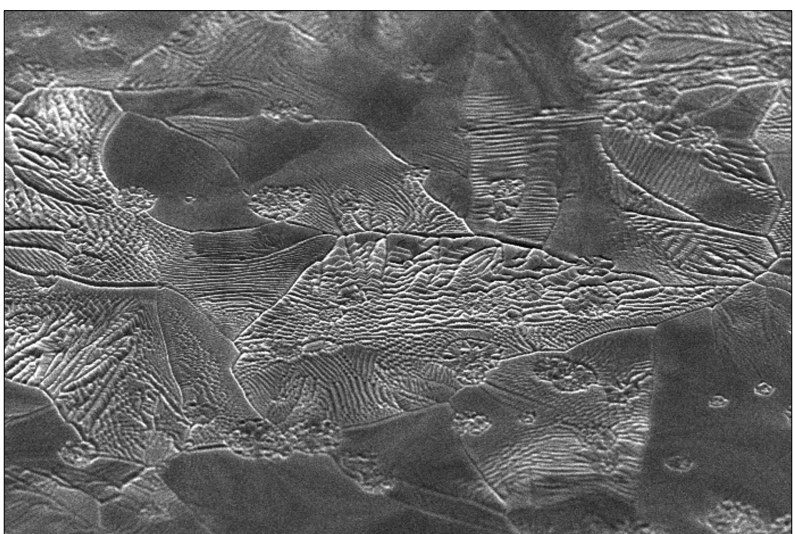

$2 \mu \mathrm{m}$

Рис. 1. Изображения поверхности пленок образцов $\mathrm{TiO}_{x}$ сразу после синтеза $(a)$ и после отжига при температуре $900^{\circ} \mathrm{C}$ в течение $10 \min (b)$ и $20 \min (c)$ в установке импульсного отжига и $120 \min (d)$ в трубчатой печи.
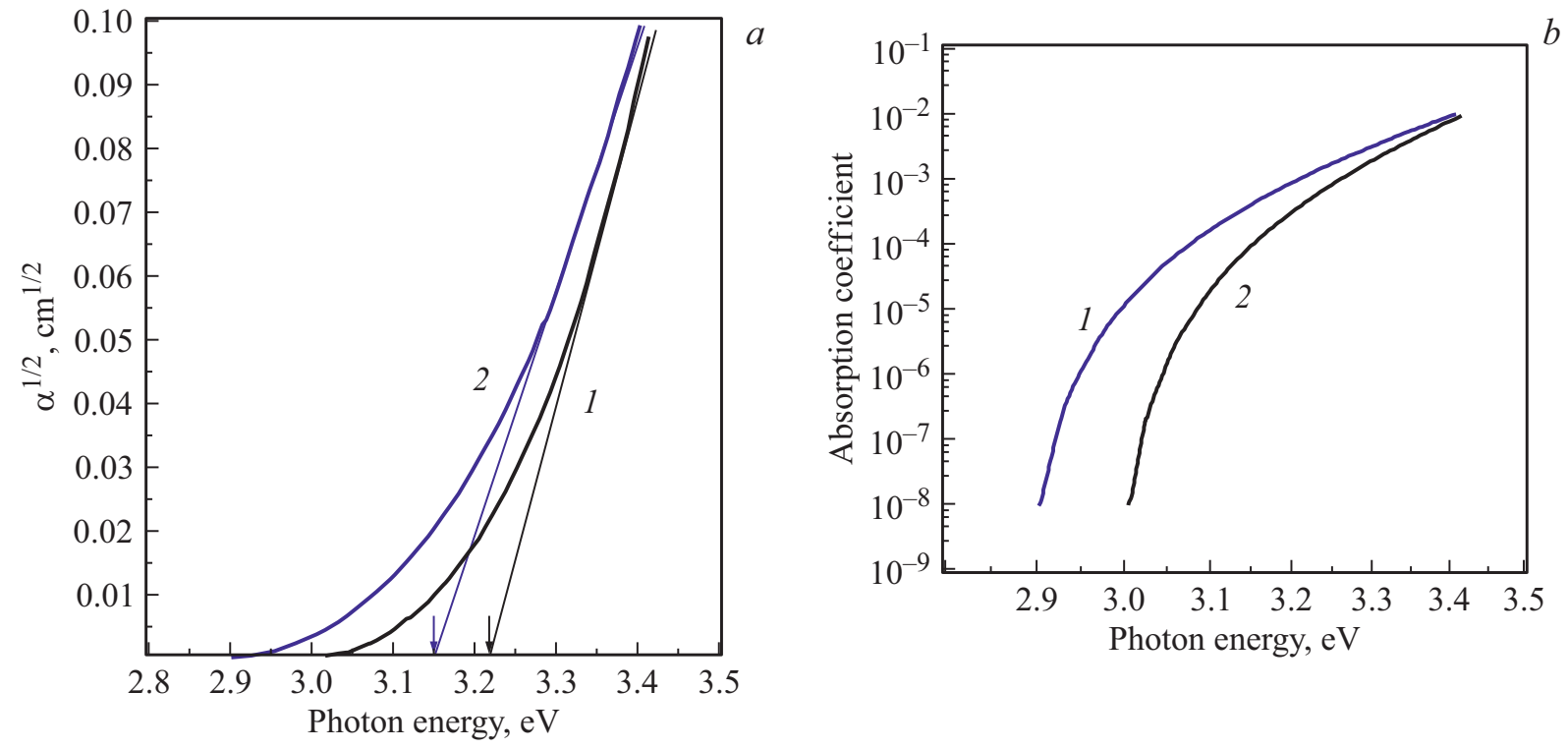

Рис. 2. Спектры поглощения сразу после синтеза (кривая 1 ) и после отжига в атмосфере кислорода при температуре $900^{\circ} \mathrm{C}$ в течение $1 \mathrm{~h}$ (кривая 2). (a) Определение ширины запрещенной зоны; (b) край Урбаха. 


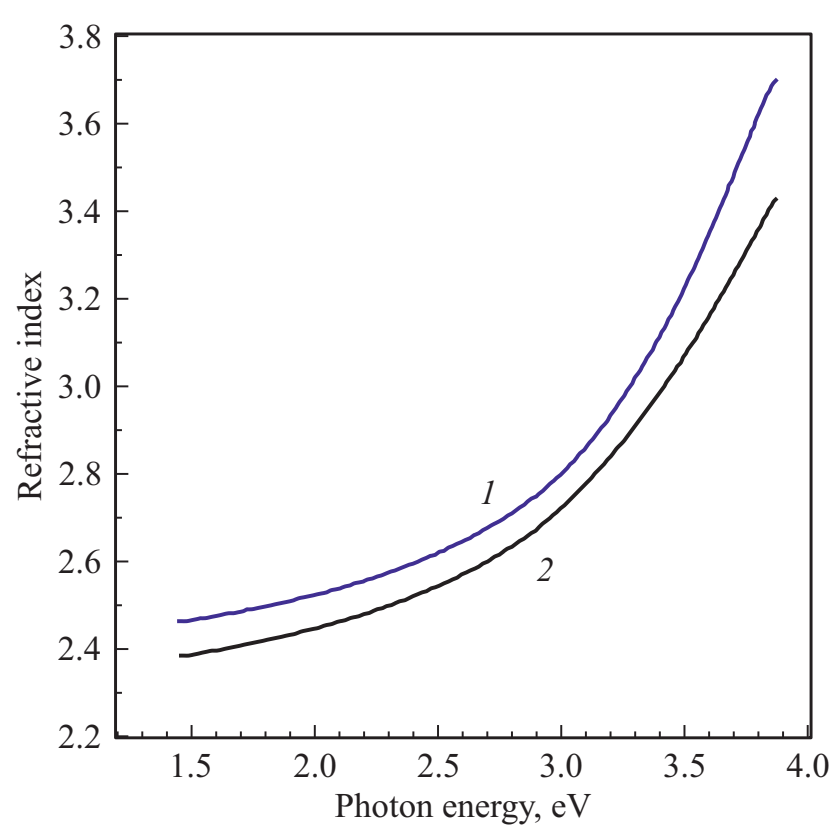

Рис. 3. Спектры показателя преломления сразу после синтеза (кривая 1) и после отжига в атмосфере кислорода при температуре $900^{\circ} \mathrm{C}$ в течение $1 \mathrm{~h}$ (кривая 2).

что при отжиге имеют место процессы кристаллизации мелких частиц в наночастицы большего размера. Таким образом, наблюдается процесс роста нанокристаллов и слияние мелкокристаллических зародышей, подобный процессу коалесценции кластеров вещества.

Пленки оксида титана отжигались в атмосфере кислорода при различных температурах. Отжиг при каждой температуре длился разное время, что позволяло изучать кинетику изменения величины показателя преломления при кристаллизации пленок. Результаты этих измерений представлены на рис. 4.

Изменение показателя преломления от времени отжига может быть описано эмпирической формулой:

$$
\Delta n=\Delta n_{\infty}[1-\exp (-t / \tau)]
$$

где $\Delta n_{\infty}-$ максимальное изменение показателя отжига при завершении процесса кристаллизации, $t-$ время отжига, $\tau$ - постоянная времени кристаллизации.

Кинетика процесса кристаллизации позволяет определить постоянную времени этого процесса $(\tau)$, в том числе это можно сделать при различных температурах отжига. Постоянная времени была одинаковой, когда ее вычисляли при различных длинах волн. Её величина не зависла от длины волны, но зависела от температуры. Она росла, когда температура падала. Величина, обратная постоянной времени процесса кристаллизации, была построена в координатах Аррениуса (рис. 5), что позволяет вычислить энергию кристаллизации оксида титана. Результат вычисления дает значение $0.6 \pm 0.1 \mathrm{eV}$.

Результаты рентгеновского фазового анализа и оптические свойства пленок показывают, что они имеют тенденцию к кристаллизации в структуре анатаза при отжиге в атмосфере кислорода. Процесс кристаллизации имеет энергию активации порядка $0.6 \mathrm{eV}$.

\section{Фотолюминесценция тонких пленок}

Фотолюминесценция пленок возбуждалась лазером с длиной волны $325 \mathrm{~nm}$. Спектры фотолюминесценции оксида титана сразу после синтеза и после отжига при температуре $900^{\circ} \mathrm{C}$ в течении $1 \mathrm{~h}$ представлены на рис. 6 .

Результаты изучения люминесценции показывают, что до и после отжига энергия максимума полосы излучения изменяются незначительно. Это изменение может быть связано с изменением ширины запрещенной зоны материала после отжига. Этот факт дает нам возможность предположить неизменность механизмов, которые определяют излучение данных полос. Дисперсия полос излучения зависит как от разупорядочения в аморфном материале, так и от величины электрон-фононного взаимодействия. Дисперсия уменьшается для всех полос при отжиге в атмосфере кислорода. Это связано с тем, что отжиг сопровождается кристаллизацией материала, а составляющая дисперсии, которая связана с аморфизацией, существенно уменьшается. Однако дисперсия полос излучения в кристаллическом материале остается значительной величиной, что указывает на ведущую роль электрон-фононного взаимодействия при формировании полос излучения в оксиде титана. Влияние электронфононного взаимодействия на излучение в оксидных материалах отмечалось в предыдущих работах. Работа [14] является одной из первых, где подробно изучаются температурные зависимости люминесценции диоксида титана в фазах анатаза и рутила и делается вывод о существенной роли электрон-фононного взаимодействия при формировании спектров излучения. Авторы работы [15] показали, что полоса $1.22 \mathrm{eV}$ в кристаллическом $\mathrm{TiO}_{2}$ связана с комплексом междоузельного титана и обусловлена сильным электрон-фононным взаимодействием. В этой работе разработана методика построения конфигурационно-координатных диаграмм на основе измеренных полос излучения.

Отжиг при высоких температурах в атмосфере кислорода приводит к протеканию двух параллельных процессов: во-первых, кислород взаимодействует с вакансиями кислорода и их концентрация на поверхности падает. Возникает градиент концентрации вакансий и это является причиной движения вакансий кислорода к поверхности, при этом поверхность обогащается атомами титана при недостатке кислорода. Во-вторых, атомы титана на поверхности взаимодействуют с кислородом реактора и возникает оксид титана, который достраивает кристаллическую решетку уже существовавших наночастиц оксида титана, которые увеличиваются в размерах и это наблюдается экспериментально, в том числе методом просвечивающей электронной микроскопии. Тенденция к многократному усилению полос излу- 
Параметры разделения спектров фотолюминесценции на составляющие

\begin{tabular}{|c|c|c|c|c|c|c|c|c|c|c|}
\hline Номер полосы & \multicolumn{2}{|c|}{1} & \multicolumn{2}{|c|}{2} & \multicolumn{2}{|c|}{3} & \multicolumn{2}{|c|}{4} & \multicolumn{2}{|c|}{5} \\
\hline Параметры, eV & $E_{1}$ & $\sigma$ & $E_{2}$ & $\sigma$ & $E_{3}$ & $\sigma$ & $E_{4}$ & $\sigma$ & $E_{5}$ & $\sigma$ \\
\hline $\begin{array}{l}\text { Сразу после } \\
\text { синтеза }\end{array}$ & 1.18 & 0.07 & 1.48 & 0.10 & 1.96 & 0.11 & 2.40 & 0.13 & 2.8 & 0.11 \\
\hline $\begin{array}{l}\text { После отжига } \\
\text { в кислороде } \\
\text { при } 900^{\circ} \mathrm{C} 1 \mathrm{~h}\end{array}$ & 1.22 & 0.052 & 1.44 & 0.08 & 1.98 & 0.10 & 2.42 & 0.11 & 2.86 & 0.10 \\
\hline
\end{tabular}

Примечание. $E_{i}$ - энергия максимума полосы излучения, $\sigma$ - дисперсия полосы излучения.
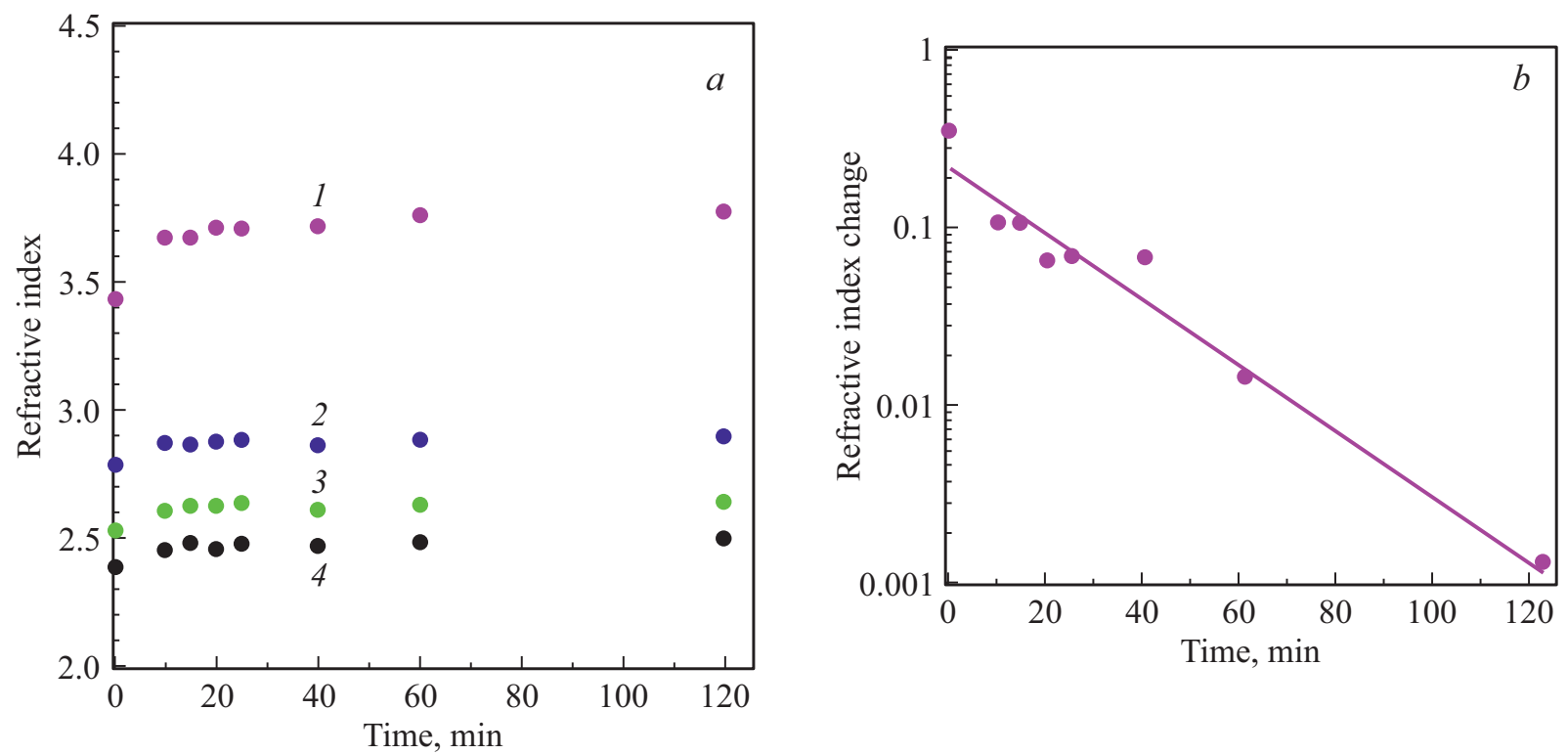

Рис. 4. Кинетика изменения показателя преломления тонких пленок оксида титана в процессе отжига при $900^{\circ} \mathrm{C}$. $(a)$ Кинетика изменения показателя, измеренного при различных длинах волн, nm: $1-321,2-400,3-500,4-850 \mathrm{~nm}$; $(b)$ кинетика изменения приращения показателя преломления за время отжига при длине волны $321 \mathrm{~nm}$.

чения (рис. 6) после отжига в кислороде обусловлена в первую очередь кристаллизацией материала, которая ведет к его упорядочению, что сокращают потери на безызлучательную рекомбинацию. Однако отжиг оказывает влияние на каждую из полос по-разному. Интенсивность полос излучения, которые связаны с электронными состояниями дефектов, изменяются не только из-за упорядочения структуры материала, но и в результате изменения концентрации дефектов. Интенсивность полосы 1 , которая связана с междоузельными ионами титана $\mathrm{Ti}^{+3}$ на поверхности нанокристаллов, увеличивается в 168 раз, а интенсивность полосы 4, которая связана с вакансиями кислорода - увеличивается в 110 раз. Это показывает тенденцию к уменьшению концентрации вакансий кислорода, но они не исчезают. Как показали результаты просвечивающей электронной микроскопии высокого разрешения, нанокристаллы остаются малыми с размерами порядка 20-40 nm и окружены они аморфной фазой, что согласуется с наличием края Урбаха на спектрах поглощения (рис. 2, $b$ ). Поэтому вакансий кислорода остается много. Интенсивность полосы 3 становится относительно меньше 1 , это связано с тем, что количество междоузельных ионов титана $\mathrm{Ti}^{+4}$ в объеме нанокристаллов снижается. Заметно падает интенсивность полосы 3, которая связана с комплексами междоузельного титана и вакансии кислорода, это указывает на то, что вакансии из объема нанокристаллов переходят на их поверхность.

Таким образом, процесс кристаллизации сопровождается движением вакансий из объема растущих нанокристаллов на их поверхность.

\section{Кинетическая модель кристаллизации оксида титана}

Нами были рассмотрены ранее модели процессов формирования нанокристаллов при отжиге в работах $[25,26]$. Пленки оксида титана сразу после синтеза магнетронным методом являются рентгеноаморфными и состоят 


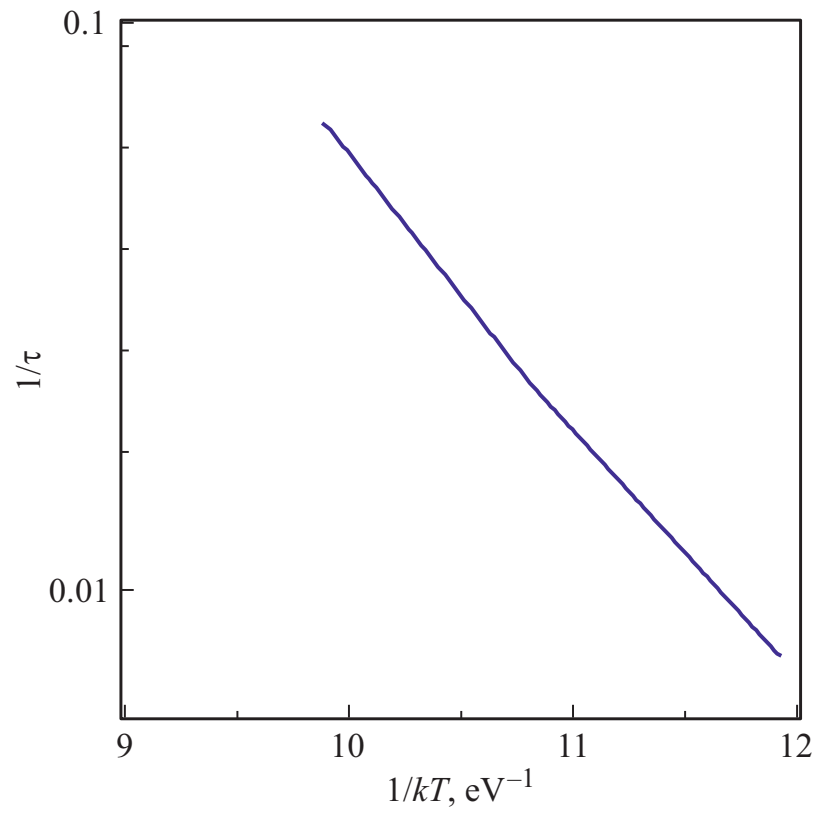

Рис. 5. Температурная зависимость величины обратной постоянной процесса кристаллизации в координатах Аррениуса.

из нанокристаллов размером менее $5 \mathrm{~nm}$, которые можно рассматривать как центры кристаллизации. Отжиг оксида титана приводит к самоорганизации атомов и вызывает следующую трансформацию: центры кристаллизации объединяются в кластеры; кластеры уплотняются и превращаются в нанокристаллы малых размеров. Затем малые нанокристаллы продолжают расти, происходит упорядочение внутри них, при этом возникает нанокристаллы большего размера $[25,26]$. Эта стадия была названа коалесценцией.

Существует две модели роста нанокристаллов: гомогенная и гетерогенная. Гомогенному образованию скоплений соответствует схема: $A_{i}+A \leftrightarrow A_{i+1}$. Эта модель подходит только для роста кристаллов, которые состоят только из одного сорта атомов, например кремния $[25,26]$. Оксид титана состоит из атомов титана и кислорода, поэтому рост его кристаллов происходит по гетерогенному механизму. Гетерогенный рост нанокристалла описывается с помощью следующего уравнения: $A_{i} C+A \leftrightarrow A_{i+1} C$ Первоначально пленка оксида титана состоит из центров кристаллизации размером менее $5 \mathrm{~nm}$. На поверхности этих центров множество оборванных связей и вакансий. Пленка отжигается в атмосфере кислорода. Взаимодействие кислорода с нанокристаллами осуществляется на поверхности этих монокристаллов. Поэтому поверхность их обедняется вакансиями кислорода. Возникает диффузионный поток вакансий кислорода к поверхности нанокристаллов, и поверхность обогащается ионами титана $\mathrm{Ti}^{+3}$. Эти ионы взаимодействуют с кислородом с образованием оксида титана, которые достаивают решетку и увеличивают размеры существующих наночастиц оксида.
Процесс движения вакансий кислорода к поверхности является определяющим, так, в конечном итоге он вызывает увеличение размеров нанокристаллов. Этот процесс можно рассматривать как уход вакансий кислорода на стоки, к которым можно отнести границы растущих монокристаллов. Центры кристаллизации захватывают атомы кислорода с образованием частиц оксида и испускают вакансии кислорода (мономеры). Этот процесс описывается с помощью системы уравнений $[25,26]$ :

$$
\begin{aligned}
& \left\{\begin{array}{l}
\frac{d N_{i}}{d t}=-N_{i}\left(k_{i} N+g_{i}\right)+g_{i+1} N_{i+1}+k_{i-1} N N_{i-1}, \\
\frac{d N}{d t}=-N \sum_{i=0} k_{i} N_{i}+\sum_{i=1} g_{i} N_{i},
\end{array}\right. \\
& N_{C}=\sum_{i=0} N_{i}(t)=\text { const, }
\end{aligned}
$$

где $N_{i}$ - средняя по объему концентрация центров кристаллизации, присоединивших $i$ частиц; $N-$ концентрация мономеров (вакансий кислорода); $k_{i} N$ и $g_{i}-$ скорости захвата и выброса мономера для центра кристаллизации, присоединившего $i$ частиц.

Увеличение размеров центров кристаллизации (формула (3)) в результате диффузии вакансий кислорода на стоки происходит на начальной стадии процесса $[25,26]$, когда формируется фрактальный кластер из центров зарождения, которые образовались в процессе синтеза, затем кластер продолжает уплотняться по-прежнему за счет ухода вакансий кислорода на стоки и происходит рост нанокристалла. Рост нанокристалла называется реакционным (формула (3)), если на границе центра зарождения существует потенциальный барьер. В этом случае уход вакансии с поверхности центра кристаллизации требует энергии, связанной с преодолением потенциального барьера. Для кинетических коэффициентов можно использовать выражения [27]:

$$
k_{i}=\left\{\begin{array}{l}
k_{D}=4 \pi D b, \\
k_{R}=\frac{4 \pi b^{2} D}{r_{0}} \exp \left\{-\frac{E_{i}}{k T}\right\},
\end{array}\right.
$$

где $k_{D}$ - вероятность ухода вакансии кислорода на поверхность растущего нанокристалла при диффузионном механизме его формирования; $k_{R}-$ вероятность ухода вакансии с центра кристаллизации при необходимости ей преодолеть потенциальный барьер, что соответствует реакционному механизму роста нанокристалла; $D$ коэффициент диффузии вакансии кислорода в веществе; $b$ - период решетки растущего нанокристалла; $r_{0}-$ радиус нанокристалла.

Концентрация центров кристаллизации сформировалась в процессе синтеза и она не меняется во времени. Поэтому можно найти точное решение (3) в следующем виде:

$$
\begin{aligned}
t= & C+{ }_{2} F_{1}\left(\alpha, \alpha, 1+\alpha,-\frac{N(0)+N_{C}-N_{E}}{N_{E}-N}\right) \\
& \times\left(\frac{N_{C}}{N_{E}-N}\right)^{\alpha} \frac{1}{k_{D} N_{C}},
\end{aligned}
$$



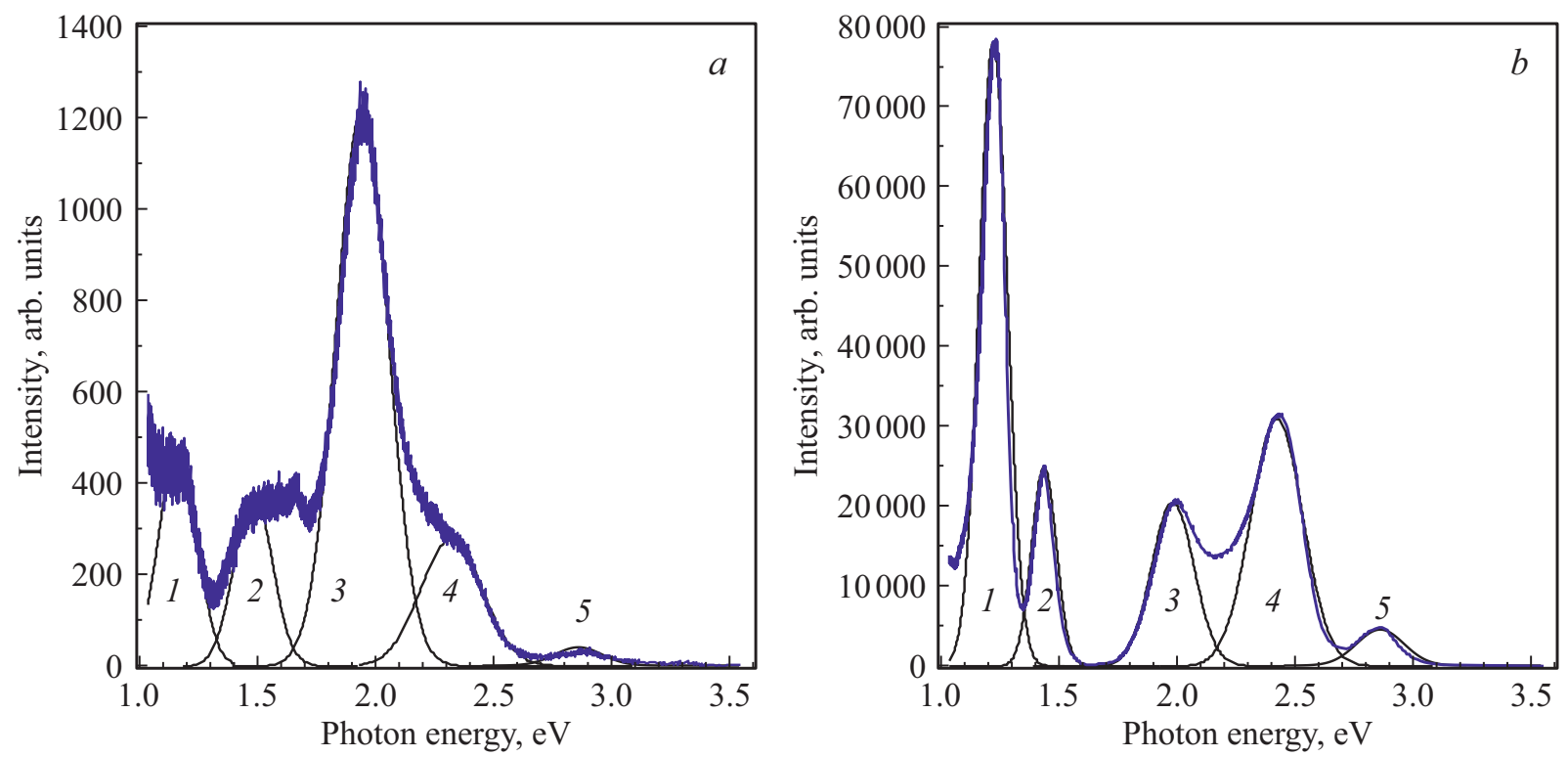

Рис. 6. Спектры фотолюминесценции образцов оксида титана сразу после синтеза $(a)$ и после отжига в атмосфере кислорода при $900^{\circ} \mathrm{C}$ в течение $1 \mathrm{~h}(b)$. Экспериментальные результаты показаны огибающей кривой, результаты разделения с помощью функции Гаусса показаны нумерованными кривыми. Параметры полос излучения показаны в таблице. Разделение спектра на отдельные пики осуществлялось с помощью распределения Гаусса. Параметры разделения показаны в таблице.

где константа определяется уравнением

$$
\begin{aligned}
C= & -{ }_{2} F_{1}\left(\alpha, \alpha, 1+\alpha,-\frac{N(0)+N_{C}-N_{E}}{N_{E}-N(0)}\right) \\
& \times\left(\frac{N_{C}}{N_{E}-N(0)}\right)^{\alpha} \frac{1}{k_{D} N_{C}} .
\end{aligned}
$$

Здесь ${ }_{2} F_{1}-$ гипергеометрическая функция, $\alpha-$ фрактальная размерность для сферического нанокристалла $\alpha=0.33, N(0)$ - начальная концентрация мономеров; $N_{E}$ - конечная равновесная концентрация мономеров; $N_{C}$ - концентрация центров зарождения, которая в данной модели считается постоянной.

Для уравнения (5) можно получить аппроксимации для начальной $(t \rightarrow 0)(6)$ и конечной $(t \rightarrow \infty)$ (7) стадии кинетики роста нанокристалла:

$$
\begin{gathered}
\frac{N(t)-N_{e}}{N(0)-N_{e}}=\exp \left\{-N_{C}\left\{(1-\alpha)\left[N(0)-N_{e}\right]^{\alpha} k_{D} t\right\}^{\frac{1}{1-\alpha}}\right\}, \\
N(t)-N_{e}=A \exp \left\{-N_{C}^{1-\alpha}\left[N(0)+m N_{C}-N_{e}\right]^{\alpha} k_{D} t\right\} .
\end{gathered}
$$

В обоих случаях температурная зависимость показателя экспоненты определяется коэффициентом диффузии мономера, а именно вакансии кислорода. Экспериментальные результаты, которые приведены на рис. 6, показывают, что энергия процесса кристаллизации составляет величину порядка $0.6 \mathrm{eV}$. Теоретический расчет показывает, что эта энергия должна определять диффузию вакансии кислорода. Авторы работы [28] сделали оценку величины энергии активации диффузии вакансий кислорода с поверхности (101) кристалла оксида титана и получили значение, которое находится в пределах от 0.6 до $1.2 \mathrm{eV}$. Значение энергии активации, полученные нами в данной работе, согласуется с этой величиной. Чем выше парциальное давление кислорода и меньше парциальное давление титана, тем выше концентрация центров кристаллизации в пленке. При их большом количестве в матрице образуется большое количество дефектов, что должно способствовать ускорению диффузии. В связи с этим коэффициент диффузии может иметь величину меньше расчетной [28], которая вычислена для монокристаллов. Соответственно величина энергии активации диффузии вакансий кислорода по пленке может находиться у нижней границы расчета, как это найдено экспериментально в нашем случае. Это дает основание предположить, что основным механизмом увеличения нанокристаллических образований в тонких пленках оксида титана является их уплотнение за счет ухода вакансий кислорода на поверхности растущих нанокристаллов. При этом отжиг вызывает образование крупных нанокристаллов с выраженными границами. Границы между монокристаллами хорошо наблюдаются экспериментально. Примером может служить рис. 1, на котором видно увеличение размеров нанокристаллов на поверхности пленок по мере увеличения длительности отжига.

Формулы (6) и (7) показывают, что на образование нанокристаллов оказывает влияние как температура (за счет температурной зависимости коэффициента диффузии вакансий кислорода), так и начальная концентрация центров кристаллизации. Эта вели- 
чина зависит от парциальных давлений кислорода и титана. Эти экспериментальные факты подтверждают, что разработанная нами теоретическая модель удовлетворительно согласуется с результатами экспериментов.

\section{Заключение}

После синтеза пленки оксида титана методом магнетронного напыления при парциальном давлении кислорода в реакторе 0.48 mTorr она состоит из мелких нанокристаллов с размерами менее $5 \mathrm{~nm}$. Отжиг пленок в атмосфере кислорода при высоких температурах заставляет вакансии кислорода уходить на поверхность растущего нанокристалла, которая обогащается ионами междоузельного титана $\mathrm{Ti}^{+3}$. Эти ионы взаимодействуют с кислородом и происходит рост нанокристаллов. Пленка постепенно уплотняется, нанокристаллы увеличиваются в размерах за счет роста и слияния соседних мелких нанокристаллов в один более крупный. Этот процесс происходит с энергией активации порядка $0.6 \mathrm{eV}$ в случае оксида титана, что соответствует энергии активации диффузии вакансии кислорода в оксиде титана Эксперименты, проведенные в данной работе, демонстрируют увеличение показателя преломления, которое свидетельствуют об уплотнении пленки при отжиге. Интенсивность излучения пленок при возбуждении фотолюминесценции растет после отжига. Интенсивность полос излучения изменяется неодинаково. Наибольший рост соответствует увеличению концентрации ионов $\mathrm{Ti}^{+3}$ на поверхности нанокристаллов оксида титана, что согласуется с предложенной моделью их роста, которая предполагает, что вакансии кислорода диффундируют к поверхности нанокристаллов, поверхность обогащается ионами $\mathrm{Ti}^{+3}$, где они взаимодействуют с кислородом, заставляя нанокристаллы увеличивать свои размеры, чем вызван рост нанокристаллов. Концентрация вакансий кислорода на поверхности падает после отжига. Так как величина удельного сопротивления определяется этими дефектами, то сопротивление пленок растет. Пленки остаются стабильными в течение длительного времени.

\section{Финансирование работы}

Работа выполнена при поддержке Минобрнауки России, проект № 0004-2019-0003, с использованием Уникальной научной установки кремний-углеродной технологии гетерогенной интеграции Института нанотехнологий микроэлектроники РАН.

\section{Конфликт интересов}

Авторы заявляют, что у них нет конфликта интересов.

\section{Список литературы}

[1] Obstarczyk A., Kaczmarek D., Wojcieszak D., Mazur M., Domaradzki J., Kotwica T., Pastuszek R., Schmeisser D., Mazur P., Kot M.T. // Materials \& Design. 2019. V. 175. P. 107822. doi 10.1016/j.matdes.2019.107822

[2] Jiang S.S., He G., Gao J., Xiao D.Q., Jin P., Li W.D., Lv J.G., Liu M., Liu Y.M., Sun Z.Q. // Ceramics International. 2016. V. 42. N 10. P. $11640-11649$. doi 10.1016/j.ceramint.2016.04.067

[3] Carpenter M.A., Mathur S., Kolmakov A. Metal Oxide Nanomaterials for Chemical Sensors. NY: Springer, 2013.

[4] Avasthi S., McClain W.E., Man G., Kahn A., Schwartz J., Sturm J.C. // Appl. Phys. Lett. 2013. V. 102. N 20. P. 203901. doi 10.1063/1.4803446

[5] Nagamatsu K.A., Avasthi S., Sahasrabudhe G., Man G., Jhaveri J., Berg A.H., Schwartz J., Kahn A., Wagner S., Sturm J.C. // Appl. Phys. Lett. 2015. V. 106. N 12. P. 123906. doi $10.1063 / 1.4916540$

[6] Wang X., Wu G., Zhou B., Shen J. // Materials (Basel, Switzerland). 2013. V. 6. N 7. P. 2819-2830. doi 10.3390/ma6072819

[7] Ju Y., Li L., Wu Z., Jiang Y. // Energy Procedia. 2011. V. 12. P. 450-455. doi 10.1016/j.egypro.2011.10.060

[8] Hoskins B.D., Strukov D.B. // J. Vacuum Science \& Technology A: Vacuum, Surfaces, and Films. 2017. V. 35. N 2. P. 20606. doi $10.1116 / 1.4974140$

[9] Dannenberg R., Greene P. // Thin Solid Films. 2000. V. 360. N 1-2. P. 122-127. doi 10.1016/S0040-6090(99)00938-4

[10] Shyjumon I., Gopinadhan M., Helm C.A., Smirnov B.M., Hippler R. // Thin Solid Films. 2006. V. 500. N 1-2. P. 41-51. doi 10.1016/j.tsf.2005.11.006

[11] Deskins N.A., Du J., Rao P. // Phys. Chem. Chem. Phys.: PCCP. 2017. V. 19. N 28. P. $18671-18684$. doi $10.1039 / \mathrm{c} 7 \mathrm{cp} 02940 \mathrm{c}$

[12] Sahbeni K., Sta I., Jlassi M., Kandyla M., Hajji M., Kompitsas M., Dimassi W. // J. Phys. Chem. \& Biophys. 2017. V. 7. N 03. doi 10.4172/2161-0398.1000257

[13] Chen H.-C., Lee K.-S., Lee C.-C. // Appl. Opt. 2008. V. 47. N 13. P. 284-7. doi 10.1364/AO.47.00C284

[14] Gallart M., Cottineau T., Hönerlage B., Keller V., Keller N., Gilliot P. // J. Appl. Phys. 2018. V. 124. N 13. P. 133104. doi 10.1063/1.5043144

[15] Bulyarskiy S.V., Gorelik V.S., Gusarov G.G., Koiva D.A., Lakalin A.V. // Opt. Spectrosc. 2020. V. 128. N 5. P. 590-595. doi 10.1134/S0030400X20050057

[16] Zhao J., Jia C., Duan H., Li H., Xie E. // J. Alloys Compd. 2008. V. 461. N 1-2. P. 447-450. doi 10.1016/j.jallcom.2007.07.018

[17] Stevanovic A., Büttner M., Zhang Z., Yates J.T. // J. American Chem. Soc. 2012. V. 134. N 1. P. 324-332. doi $10.1021 /$ ja2072737

[18] Preclíková J., Galár̆ P., Trojánek F., Daniš S., Rezek B., Gregora I., Němcová Y., Malý P. // J. Appl. Phys. 2010. V. 108. N 11. P. 113502. doi 10.1063/1.3512982

[19] Knorr F.J., Mercado C.C., McHale J.L. // J. Phys. Chem. C. 2008. V. 112. N 33. P. 12786-12794. doi 10.1021/jp8039934

[20] Wang X., Feng Z., Shi J., Jia G., Shen S., Zhou J., Li C. // Phys. Chem. Chem. Phys.: PCCP. 2010. V. 12. N 26. P. 7083-7090. doi 10.1039/b925277k

[21] Mercado C.C., Knorr F.J., McHale J.L. // ACS Nano. 2012. V. 6. N 8. P. 7270-7280. doi 10.1021/nn302392p 
[22] Mercado C., Seeley Z., Bandyopadhyay A., Bose S., McHale J.L. // ACS Appl. Mater. \& Interfaces. 2011. V. 3. N 7. P. 2281-2288. doi 10.1021/am2006433

[23] Santara B., Giri P.K., Imakita K., Fujii M. // J. Phys. Chem. C. 2013. V. 117. N 44. P. 23402-23411. doi 10.1021/jp408249q

[24] Henderson M.A. // Surface Science. 1995. V. 343. N 1-2. L1156-L1160. doi 10.1016/0039-6028(95)00849-7

[25] Bulyarskiy S.V., Svetukhin V.V. // J. Nanoparticle Research. 2020. V. 22. N 12. doi 10.1007/s11051-020-05069-1

[26] Bulyarskiy S.V., Svetukhin V.V. // Silicon. 2020. V. 13 P. $3321-3327$. doi 10.1007/s12633-020-00703-y

[27] Johnson W.L., Sankey O.F., Dow J.D. // Phys. Rev. B. 1984. V. 30. N 4. P. 2070-2073. doi 10.1103/PhysRevB.30.2070

[28] Scheiber P., Fidler M., Dulub O., Schmid M., Diebold U., Hou W., Aschauer U., Selloni A. // Phys. Rev. Lett. 2012. V. 109. N 13. P. 136103.

doi 10.1103/PhysRevLett.109.136103 